\title{
Impact of Maximum Air Temperature on Ambulance Transports Owing to Heat Stroke During Spring and Summer in Tottori Prefecture, Japan: A Time-stratified Case-crossover Analysis
}

\author{
Yusuke Fujitani,* Shinji Otani, $†$ Abir Majbauddin, $†$ Hiroki Amano,* Toshio Masumoto* and Youichi Kurozawa* \\ *Division of Health Administration and Promotion, Department of Social Medicine, School of Medicine, Tottori University Faculty of \\ Medicine, Yonago 683-8504, Japan, and †International Platform for Dryland Research and Education, Tottori University, Tottori 680- \\ 0001, Japan
}

\section{ABSTRACT}

Background The frequency and intensity of hot weather have increased. In Japan, there have been many studies of the relationship between ambulance transports owing to heat stroke (ATHS) and high air temperature in the summer season. However, there have been very few reports focusing on ATHS in spring. Therefore, we investigated the effect of the maximum air temperature on ATHS not only in summer but also in spring, to help with development of effective measures to prevent heat stroke.

Methods We obtained daily ATHS and meteorological data from April to September in 2017 in Tottori Prefecture. We used a time-stratified case-crossover method for data analysis.

Results A total 382 cases of ATHS were identified from April to September in 2017 in Tottori. The number of cases was highest in July, followed by August and May. Maximum air temperature was significantly linked to ATHS. The risk of ATHS was increased 1.13 times when maximum air temperature rose by $1^{\circ} \mathrm{C}$. In summer, the risk on extremely hot days (maximum air temperature $\geq 35^{\circ} \mathrm{C}$ ) increased by 5.55 times or more compared with that on days below $30^{\circ} \mathrm{C}\left(<30^{\circ} \mathrm{C}\right)$. The risk was approximately four times greater on hot days $(\geq$ $30^{\circ} \mathrm{C}$ and $\left.<35^{\circ} \mathrm{C}\right)$ than that on relatively cooler days $(<$ $30^{\circ} \mathrm{C}$ ) during the spring months of April through May.

Conclusion Maximum air temperature was significantly linked to ATHS. It is necessary to pay particular attention to heat stroke prevention not only on extremely hot days in summer but also on hot days in the spring.

Key words ambulance transport; case-crossover study; heat stroke; maximum air temperature

The frequency and intensity of hot weather have increased. ${ }^{1}$ In Japan, there have been studies of the relationship between ambulance transports owing to heat stroke (ATHS) and high air temperature in the summer season. ${ }^{2-8}$ These studies have reported a strong correlation between ATHS and daily maximum temperature.
According to the Japan Meteorological Agency, ${ }^{9}$ the annual number of days with maximum temperatures of $\geq$ $30^{\circ} \mathrm{C}$ (hot days) is highly likely to have increased and the number with maximum temperatures $\geq 35^{\circ} \mathrm{C}$ (extremely hot days) is virtually certain to have increased. "Extreme High Temperature Forecasts" are issued for prefectures where the maximum temperature for the day is expected to exceed $35^{\circ} \mathrm{C}$, so that measures to prevent heat stroke can be adopted..$^{10}$

Most previous studies have focused on ATHS and high air temperatures in the summer. ${ }^{2-8}$ There have been very few reports focusing on heat stroke during the spring. The seasonal mean temperatures in spring have risen at rates of about $1.4^{\circ} \mathrm{C}$ per century. ${ }^{9}$ It is necessary to expand the analysis during only summer months and include spring months, to develop effective preventive measures of heat stroke. In Tottori Prefecture in Japan, many cases of ATHS were observed in 2017. There were also a considerable number of such cases during spring months in Tottori. Therefore, we investigated the effect of maximum air temperature on ATHS not only during summer months but also during the spring in Tottori Prefecture.

The time-stratified case-crossover design has been previously used to examine short-term exposures with acute outcomes. ${ }^{11-12}$ This design includes only cases and compares an individual's exposure just prior to an event with exposure at a different time (referent) period. This method has been increasingly used to examine the short term effects of air pollution on cardiovascular and respiratory diseases as well as asthma events. ${ }^{13-14}$ This approach has also been used to investigate the effect of extreme heat exposure on risk of emergency room visits $^{15}$ as well as injury risk among outdoor agricultural workers. ${ }^{16}$ In Japan, however, the time-stratified case-crossover design has not been used to examine heat

Corresponding author: Youichi Kurozawa, MD, PhD

kurozawa@tottori-u.ac.jp

Received 2018 December 3

Accepted 2018 December 27

Abbreviations: ATHS, ambulance transports owing to heat stroke; $\mathrm{CI}$, confidence interval; $\mathrm{OR}$, odds ratio 
stroke and climate factors. Therefore, we applied the time-stratified case-crossover method to investigate the effect of maximum air temperature on ATHS.

\section{MATERIALS AND METHODS Study site}

The present study was conducted in Tottori Prefecture, which is located on the Japan Sea coast in the Chugoku region of southwest Japan. The prefecture covers 3507 $\mathrm{km}^{2}$, and its population was 567,000 in $2017 .{ }^{17}$ Air temperatures are usually above $30^{\circ} \mathrm{C}$ during July and August. The coastline of Tottori Prefecture traditionally receives snowfall in winter.

\section{Ambulance transport data}

We obtained data of daily ATHS from April to September in 2017 from all 26 fire stations in Tottori Prefecture. These data were collected through the Department of Health and Welfare of the Tottori prefectural government. Each case record includes information regarding age and sex, date and time of ambulance transport, as well as medical condition and initial diagnosis. The medical condition and initial diagnosis were determined by an emergency medical doctor upon the patient's arrival at the hospital. Medical condition consists of five categories: mild, moderate, severe, dead, and other. The diagnosis of heat stroke was made by an emergency department physician, based on the first presentation of the patient in the emergency department. Ambulance transport data included individuals living outside of Tottori Prefecture, but these data were excluded from this study.

\section{Meteorological data}

Meteorological data regarding daily air temperature and relative humidity, hours of sunlight, precipitation, average wind speed, and "deviation" in Tottori Prefecture were provided by the Japan Meteorological Agency. Deviation is the difference between the maximum temperature and the average maximum temperature over the past 30 years (1981-2010). ${ }^{18}$

The meteorological observation sites were located in three districts of Tottori Prefecture, as follows: the Eastern district (Tottori City, Iwami Town, Yazu Town, Wakasa Town, and Chizu Town), Central district (Kurayoshi City, Hokuei Town, Misasa Town, Kotoura Town, and Yurihama Town), and Western district (Yonago City, Sakaiminato City, Daisen Town, Hoki Town, Nanbu Town, Kofu Town, Nichinan Town, Hino Town, and Hiezu Village). We used meteorological data of the nearest observation point corresponding to the location of each ambulance transport case.

\section{Statistical analysis}

We first performed descriptive analysis. Ambulance transport cases were further grouped by sex and age group: children $(<18$ years), adults $(\geq 18$ years and $<65$ years), and elderly people ( $\geq 65$ years). We calculated the number of ambulance transport cases per 1,000 residents, using the estimated population of Tottori Prefecture on 1 October 2017, by sex and age group. ${ }^{17}$

Next, we analyzed the effect of maximum air temperature on ATHS using the time-stratified case-crossover approach. The case-crossover design proposed by Maclure ${ }^{11}$ is useful for studying the effects of transient exposures on short-term risk of diseases or injuries when only data on cases are available. The crossover nature of this design allows each ambulance transport case to serve as its own control. Time-stratified referent selection is recommended, to ensure unbiased estimates from conditional logistic regression and to avoid bias resulting from time trend. ${ }^{12}$ We thus selected control periods from the same times on other days, on the same days of the week, and in the same months. We used conditional logistic regression to estimate odds ratios (ORs) and 95\% confidence intervals (CIs) for the effect of maximum air temperature on ATHS.

Analyses were conducted using IBM SPSS version 24.0 (IBM, Armonk, NY).

\section{Ethical approval}

The study was approved by the Tottori University Ethics Committee (No. 180626-069).

\section{RESULTS \\ Descriptive analysis results}

Table 1 shows the number of ATHS cases by sex, age group, and month. In total, 382 cases were identified from April to September in 2017 in Tottori Prefecture. According to age group, 63 cases involved children $(<$ 18 years), 80 patients were adults ( $\geq 18$ years and $<65$ years), and 239 were elderly people ( $\geq 65$ years). The highest number of cases was in July, followed by August and May. Table 1 also shows the number of ATHS cases per 1,000 residents, by age group. The number of cases per 1,000 residents was highest among elderly residents, followed by children and adults. In the adult age group, the number of cases per 1,000 residents among male patients was three times greater than that among female patients.

\section{Meteorological results}

Table 2 shows a summary of the daily maximum air temperatures in the three districts of Tottori Prefecture for the study period. Mean daily maximum air tem- 
Table 1. Number of ambulance transport cases owing to heat stroke, by sex, age group, and month

\begin{tabular}{|c|c|c|c|c|c|c|c|c|}
\hline & Apr & May & Jun & Jul & Aug & Sep & Total & Case/1,000 \\
\hline \multicolumn{9}{|l|}{ Male } \\
\hline Children $(<18)$ & 1 & 3 & 0 & 10 & 13 & 4 & 31 & 0.689 \\
\hline Adults (18-64) & 1 & 3 & 3 & 29 & 22 & 2 & 60 & 0.400 \\
\hline Elderlies $(\geq 65)$ & 4 & 4 & 6 & 60 & 47 & 4 & 125 & 1.726 \\
\hline Total & 6 & 10 & 9 & 99 & 82 & 10 & 216 & 0.800 \\
\hline \multicolumn{9}{|l|}{ Female } \\
\hline Children $(<18)$ & 1 & 2 & 2 & 20 & 7 & 0 & 32 & 0.743 \\
\hline Adults (18-64) & 0 & 4 & 0 & 9 & 7 & 0 & 20 & 0.134 \\
\hline Elderlies $(\geq 65)$ & 1 & 14 & 10 & 53 & 36 & 0 & 114 & 1.127 \\
\hline Total & 2 & 20 & 12 & 82 & 50 & 0 & 166 & 0.562 \\
\hline
\end{tabular}

Table 2. Summary of daily maximum air temperature in three districts of Tottori Prefecture during the study period

\begin{tabular}{|c|c|c|c|c|c|c|}
\hline & $\begin{array}{l}\text { Mean daily maximum } \\
\text { temperarture }\left({ }^{\circ} \mathrm{C}\right)\end{array}$ & $\begin{array}{l}\text { Debiation } \\
\left({ }^{\circ} \mathrm{C}\right)\end{array}$ & $\begin{array}{l}\text { Maximun value } \\
\left({ }^{\circ} \mathrm{C}\right)\end{array}$ & $\begin{array}{l}\text { Minimun value } \\
\left({ }^{\circ} \mathrm{C}\right)\end{array}$ & $\begin{array}{l}\text { Hot day } \\
\text { (days) }\end{array}$ & $\begin{array}{l}\text { Extremely hot } \\
\text { day (days) }\end{array}$ \\
\hline \multicolumn{7}{|l|}{ Eastern district } \\
\hline April & 20.1 & 1.4 & 30.0 & 13.4 & 1 & 0 \\
\hline May & 25.4 & 2.1 & 31.6 & 18.5 & 4 & 0 \\
\hline June & 27.0 & 0.4 & 31.7 & 22.0 & 4 & 0 \\
\hline July & 32.8 & 2.4 & 37.2 & 26.0 & 28 & 6 \\
\hline August & 32.6 & 0.4 & 37.8 & 26.3 & 26 & 7 \\
\hline September & 27.2 & -0.2 & 30.3 & 20.1 & 1 & 0 \\
\hline April-September & 27.6 & 1.1 & 37.8 & 13.4 & 64 & 13 \\
\hline \multicolumn{7}{|l|}{ Central district } \\
\hline April & 18.8 & 1.4 & 30.1 & 11.3 & 1 & 0 \\
\hline May & 23.8 & 1.7 & 28.7 & 17.3 & 0 & 0 \\
\hline June & 24.3 & -0.9 & 30.9 & 19.8 & 1 & 0 \\
\hline July & 30.7 & 1.8 & 34.6 & 24.5 & 18 & 0 \\
\hline August & 30.4 & 0.1 & 34.7 & 26.0 & 15 & 0 \\
\hline September & 25.5 & -0.8 & 27.9 & 19.8 & 0 & 0 \\
\hline April-September & 25.6 & 0.6 & 34.7 & 11.3 & 35 & 0 \\
\hline \multicolumn{7}{|l|}{ Western district } \\
\hline April & 19.8 & 1.7 & 29.8 & 12.9 & 0 & 0 \\
\hline May & 25.3 & 2.7 & 31.9 & 19.0 & 2 & 0 \\
\hline June & 25.8 & 0.2 & 32.6 & 21.6 & 2 & 0 \\
\hline July & 32.3 & 2.6 & 35.9 & 26.8 & 27 & 6 \\
\hline August & 32.1 & 0.8 & 37.8 & 27.0 & 25 & 6 \\
\hline September & 26.8 & 0.1 & 30.0 & 21.6 & 1 & 0 \\
\hline April-September & 27.1 & 1.4 & 37.8 & 12.9 & 57 & 12 \\
\hline
\end{tabular}

"Hot day": A day on which the temperature rises above $30^{\circ} \mathrm{C}$

"Extremely hot day": A day on which the temperature rises above $35^{\circ} \mathrm{C}$

peratures were usually highest in July, followed by August and September. The monthly average maximum temperature in Yonago City exceeded the average in all months; in May and July, this exceeded the average yearly temperature. From April to September in 2017, 64 hot days and 13 extremely hot days were observed in Tottori City, 64 hot days and no extremely hot days in Kurayoshi City, and 57 hot days and 12 extremely hot days in Yonago City.
The mean daily relative humidity was 63\% (32\%$80 \%$ ) in April to May and $74 \%$ (54\%-93\%) in June to September.

\section{Case-crossover analysis results}

We investigated the relationship between ATHS and climate factors such as the maximum air temperature, relative humidity, hours of sunlight, precipitation, and average wind speed. Only the maximum air temperature 
Table 3. Effect of various meteorological factors on ambulance transports owing to heat stroke

\begin{tabular}{|c|c|c|c|c|}
\hline \multirow{2}{*}{ Meteorological data } & \multirow{2}{*}{ Odds ratios } & \multicolumn{2}{|c|}{$95 \%$ confidence intervals } & \multirow{2}{*}{$P$} \\
\hline & & Lower & Upper & \\
\hline Maximum air temperature & 1.13 & 1.05 & 1.20 & $<0.001$ \\
\hline Relative humidity & 1.01 & 0.97 & 1.05 & 0.823 \\
\hline Hours of sunlight & 1.05 & 0.98 & 1.13 & 0.135 \\
\hline Precipitation & 0.99 & 0.98 & 1.01 & 0.513 \\
\hline Mean wind speed & 1.12 & 0.79 & 1.59 & 0.522 \\
\hline
\end{tabular}

Table 4. Comparison of odds ratio for each maximum air temperature

\begin{tabular}{ccccc}
\hline \multirow{2}{*}{ Maximum air temperature } & Odds ratios & \multicolumn{2}{l}{$95 \%$ confidence intervals } & $P$ \\
& & Lower & Upper & - \\
\hline$<30^{\circ} \mathrm{C}$ & 1.00 & - & - & 0.001 \\
$30^{\circ} \mathrm{C} \leq \mathrm{t}<31^{\circ} \mathrm{C}$ & 2.55 & 1.50 & 4.32 & $<0.001$ \\
$31^{\circ} \mathrm{C} \leq \mathrm{t}<32^{\circ} \mathrm{C}$ & 2.79 & 1.72 & 4.52 & $<0.001$ \\
$32^{\circ} \mathrm{C} \leq \mathrm{t}<33^{\circ} \mathrm{C}$ & 3.16 & 1.80 & 5.57 & $<0.001$ \\
$33^{\circ} \mathrm{C} \leq \mathrm{t}<34^{\circ} \mathrm{C}$ & 4.11 & 2.42 & 6.99 & $<0.001$ \\
$34^{\circ} \mathrm{C} \leq \mathrm{t}<35^{\circ} \mathrm{C}$ & 4.58 & 2.75 & 7.65 & $<0.001$ \\
$35^{\circ} \mathrm{C} \leq \mathrm{t}<36^{\circ} \mathrm{C}$ & 5.55 & 3.16 & 9.77 & $<0.001$ \\
$36^{\circ} \mathrm{C} \leq \mathrm{t}<37^{\circ} \mathrm{C}$ & 8.64 & 4.49 & 16.66 & $<0.001$ \\
$37^{\circ} \mathrm{C} \leq$ & 17.26 & 7.68 & 38.77 & \\
\hline
\end{tabular}

Table 5. Effect of maximum air temperature on ambulance transports owing to heat stroke, by season and age group

\begin{tabular}{|c|c|c|c|c|c|c|}
\hline \multirow{2}{*}{ Season } & \multirow{2}{*}{ Age group } & \multirow{2}{*}{$\begin{array}{l}\text { Maximum air } \\
\text { temperature }\end{array}$} & \multirow{2}{*}{ Odds ratios } & \multicolumn{2}{|c|}{$95 \%$ confidence intervals } & \multirow{2}{*}{$P$} \\
\hline & & & & Lower & Upper & \\
\hline \multirow[t]{2}{*}{ Spring (Apr-May) } & Elderlies $(65 \leq)$ & $30^{\circ} \mathrm{C} \leq$ & 3.96 & 1.35 & 11.63 & 0.012 \\
\hline & Others $(<65)$ & $30^{\circ} \mathrm{C} \leq$ & 3.87 & 1.38 & 10.86 & 0.010 \\
\hline \multirow[t]{2}{*}{ Summer (Jun-Sep) } & Elderlies $(65 \leq)$ & $30^{\circ} \mathrm{C} \leq$ & 1.87 & 1.27 & 2.77 & 0.002 \\
\hline & Others $(<65)$ & $30^{\circ} \mathrm{C} \leq$ & 1.89 & 1.16 & 3.07 & 0.011 \\
\hline \multirow[t]{2}{*}{ Spring (Apr-May) } & Elderlies $(65 \leq)$ & $35^{\circ} \mathrm{C} \leq$ & - & - & - & - \\
\hline & Others $(<65)$ & $35^{\circ} \mathrm{C} \leq$ & - & - & - & - \\
\hline \multirow[t]{2}{*}{ Summer (Jun-Sep) } & Elderlies $(65 \leq)$ & $35^{\circ} \mathrm{C} \leq$ & 2.28 & 1.70 & 3.07 & $<0.001$ \\
\hline & Others $(<65)$ & $35^{\circ} \mathrm{C} \leq$ & 1.98 & 1.34 & 2.93 & 0.001 \\
\hline
\end{tabular}

was significantly related to ATHS (Table 3). As maximum air temperature rose by $1^{\circ} \mathrm{C}$, the $\mathrm{OR}$ increased 1.13 times. In addition, we attempted analysis based on the difference of the maximum temperature the day before, but no significant correlation was obtained.

We investigated the risk of ATHS on days when the maximum air temperature was over $30^{\circ} \mathrm{C}$. Table 4 shows that the OR of ATHS increases with each $1^{\circ} \mathrm{C}$ increase compared to when the temperature is less than $30^{\circ} \mathrm{C}$. When comparing maximum air temperatures to $<30^{\circ} \mathrm{C}$, the OR was 2.55 at $\geq 30^{\circ} \mathrm{C}$ and 5.55 at $\geq 35^{\circ} \mathrm{C}$ with a rectilinear change. However, the OR dramatically increased to 8.64 and 17.26 at $\geq 36^{\circ} \mathrm{C}$ and $\geq 37^{\circ} \mathrm{C}$, respectively.

Table 5 shows the effects of maximum air temperature on ATHS by season and age group. The study period was classified into the spring season (from April to May) and summer season (from June to September). ORs among elderly people and other age groups were 3.96 and 3.87 on hot days (maximum air temperature $\geq 30^{\circ} \mathrm{C}$ and $<35^{\circ} \mathrm{C}$ ), respectively, compared with other days from April to May. However, these ORs were 1.87 and 1.89 , respectively, on days with maximum air temperature $\geq 30^{\circ} \mathrm{C}$ during spring months from June to September. ORs among elderly people and other age groups were 2.28 and 1.98 , respectively, on extremely hot days compared with other days in summer.

The symptoms of patients transported by ambulance because of heat stroke ranged from mild to severe. Mild symptoms included general fatigue and headaches rather than symptoms of heat stroke. Therefore, we performed 
a similar analysis, but excluding mild cases; the results were the same as in the analysis including mild cases.

\section{DISCUSSION}

The results of our analysis indicated that elderly people in Tottori Prefecture were the most frequently transported by ambulance owing to heat stroke, followed by children; the fewest ATHS cases were among adults. These findings are consistent with those of previous studies. ${ }^{8,19-21}$ Children and elderly adults are particularly vulnerable to heat stress, and we found an elevated number of ATHS cases involving these populations. One reason for increased vulnerability to heat among elderly people is their reduced heat dissipation capacity as a result of decreased skin blood flow, decreased sweat gland function, depletion of body fluids, and decreased cardiac output. ${ }^{22}$ Physical function development in children is immature, making them more susceptible to heat stress. ${ }^{8}$ In the adult age group, the number of male cases per 1,000 residents was three times greater than the number of female cases. This pattern may be tied to the fact that men engage in more outdoor activities than females, even on days with high temperatures. ${ }^{23}$

Case-crossover analysis in the present study indicated that the number of ATHS cases rose in accordance with increases in daily maximum temperature. This result is in agreement with those of previous studies. The risk of ATHS increased by 1.13 times (13\% increase) for each $1^{\circ} \mathrm{C}$ increase in temperature. In a study conducted in the Kanto area of Japan, ${ }^{6}$ the risk of ATHS was increased by $1.09-1.49$ times for each $1^{\circ} \mathrm{C}$ rise in temperature. A report in Toronto, Canada indicated that emergency calls increased by $20 \%$ as the mean daily maximum temperature increased by $1^{\circ} \mathrm{C} .{ }^{24}$ These results were similar to our study findings.

Currently, "Extreme High Temperature Forecasts" are issued in Japanese prefectures where the maximum temperature for the day is expected to exceed $35^{\circ} \mathrm{C}$ (extremely hot days). ${ }^{10}$ In our study, the risk of ATHS was increased by 5.55 times on extremely hot days compared with other days. The annual number of extremely hot days has greatly increased since about the mid-1990s. ${ }^{10}$ Accordingly, there is concern about an increase in the occurrence of heat stroke. In addition, it was found that the risk of heat stroke increases dramatically when the maximum temperature was $36^{\circ} \mathrm{C}$ or above. In the near future, more serious warning information should be provided for high air temperatures that exceed average body temperature $\left(37^{\circ} \mathrm{C}\right)$.

In this study, we also found that the heat stroke risk was approximately four times greater on hot days than that on other days during spring months from April to May. In the abovementioned Kanto study, ${ }^{6}$ most ATHS cases occurred in August, in tandem with peak temperatures, and the increased risk of ATHS began as early as June. Our findings indicate that heat-related risk increases begin as early as the months of April and May in Tottori Prefecture. Recently, the annual number of hot days in the spring has tended to increase. ${ }^{9}$ It is necessary to pay particular attention to heat stroke prevention, even in the spring season.

We investigated the effect of maximum air temperature on ATHS from April to September in Tottori Prefecture, Japan using a time-stratified case-crossover approach. We found that maximum air temperature was significantly linked to ATHS. The risk of ATHS increased 5.55 times on extremely hot days, compared with other days from April to September. This risk was approximately four times greater on hot days than that on other days during the spring, from April to May. Particular attention is needed to prevent heat stroke not only on extremely hot days in the summer but also on hot days during the spring season.

\section{Study limitations}

This study has several limitations. First, because the meteorological data were collected at representative observation points in the three districts, the actual temperatures might not be reflected for each individual case. Second, there is a limitation owing to ambulance transport data. Selection of heat stroke cases in this study relied on the first diagnosis by a clinician upon initial presentation. These early diagnoses may have eventually changed in some cases. We did not include cases with heat-related diseases who did not use an ambulance; however, the use of ambulance transport as an indicator of health effects, other than mortality, during heat episodes is important, to achieve a wider view of the effects of biometeorological discomfort on human health, and this information may be suitable for establishing realtime surveillance systems. ${ }^{25}$ Third, we analyzed daily ATHS and meteorological data during 2017 in Tottori Prefecture. The results may not be generalized to other geographical regions. Further study is needed to investigate the relationship between heat stroke and climate factors in various regions over several years.

Acknowledgments: Ambulance transport data in this study were provided by the Department of Health and Welfare of the Tottori Prefectural Government. We thank Analisa Avila, ELS, of Edanz Group (www.edanzediting.com/ac) for editing a draft of this manuscript.

The authors declare no conflict of interest. 


\section{REFERENCES}

1 IPCC. Climate change 2013: the physical science basis. Contribution of working group I to the fifth assessment report of the intergovernmental panel on climate change. Cambridge: Cambridge University Press; 2013. p. 1535.

2 Miyatake N, Nakao M, Sakano N, Suna S, Suzue T, Hirao T. Higher temperatures were closely associated with higher ambulance transports in Takamatsu area, Japan. J Environ Protect. 2011;2:72-5. DOI: 10.4236/jep.2011.21007.

3 Miyatake N, Nakao M, Sakano N, Murakami S. The relation between ambulance transports stratified by heat stroke and air temperature in all 47 prefecture of Japan in August, 2009: ecological study. Environ Health Prev Med. 2012;1:77-80. PMID: 21611887.

4 Murakami S, Miyatake N, Sakano N. Changes in air temperature and its relation to ambulance transports due to heat stroke in all 47 prefectures of Japan. J Prev Med Public Health. 2012;45:309-15. DOI: 10.3961/jpmph.2012.45.5.309.

5 Miyatake N, Sakano N, Murakami S. The relation between ambulance transports due to heat stroke and air temperature using daily data in Okayama prefecture, Japan. Open J Prev Med. 2012;2:112-5. DOI: 10.4236/ojpm.2012.21016.

$6 \mathrm{Ng} \mathrm{CF}$, Ueda K, Ono M, Nitta H, Takami A. Characterizing the effect of summer temperature on heatstroke-related emergency ambulance dispatches in the Kanto area of Japan. Int J Biometeorol. 2014;58:941-8. PMID: 23700200.

7 Kotani K, Ueda K, Seposo X, Yasukochia S, Matsumotob $\mathrm{H}$, Ono $\mathrm{M}$, et al. Effects of high ambient temperature on ambulance dispatches in different age groups in Fukuoka, Japan Global health Action. 2018;11:1437882. DOI: 10.1080/16549716.2018.1437882.

8 Ito Y, Akahane M, Imamura T. Impact of temperature in summer on emergency transportation for Heat-Related Diseases in Japan. Chin Med J (Engl). 2018;131:574-82. PMID: 29483392.

9 Hashida T. Climate Change Monitoring Report 2017; Chapter 2 Climate Change [Internet]. Tokyo: Japan Meteorological Agency [cited 2018 Nov 1]. Available from: http://www.jma. go.jp/jma/en/NMHS/ccmr/4_ccmr2017_chapter2.pdf.

10 Japan Meteorological Agency [Internet]. Tokyo: Japan Meteorological Agency [cited 2018 Nov 1]. [Extreme High Temperature Forecasts]. Available from: https://www.data. jma.go.jp/fcd/yoho/data/kouon/. Japanese.

11 Maclure. M. The case-crossover design: a method for studying transient effects on the risk of acute events. American Journal of Epidemiology. 1991;133:144-53. PMID: 1985444.

12 Janes H, Sheppard L, Lumley T. Case-crossover analyses of air pollution exposure data: referent selection strategies and their implications for bias. Epidemiology. 2005;16:717-26. PMID: 16222160.

13 Zhang Q, Qi W, Yao W, Wang M, Chen Y, and Zhou Y. Ambient particulate matter (PM2.5/PM10) exposure and emergency department visits for acute myocardial infarction in chaoyang district, beijing, China during 2014: a case-crossover Study. J Epidemiology. 2016;26:538-45. PMID: 27064131.

14 Liu ST, Liao CY, Kuo CY, Kuo HW. The effects of PM2.5 from Asian dust storms on emergency room visits for cardiovascular and respiratory diseases. Int $\mathrm{J}$ Environ Res Public Health. 2017;14:428. PMID: 28420157.

15 Basu R, Pearson D, Malig B, Broadwin R, Green R. The effect of high ambient temperature on emergency room visits. Epidemiology. 2012;23:813-20. PMID: 23007039.

16 Spector JT, Bonauto DK, Sheppard L, Busch-Isaksen T, Calkins M, Adams D, et al. A case-crossover study of heat exposure and injury risk in outdoor agricultural workers. PLoS One. 2016;11;e0164498. PMID: 27716794.

17 Tottori Prefecture. [Population estimate by Tottori prefecture age group] [Internet]. Tottori: Tottori Prefecture; [cited 2018 Nov 1]. Available from: https://www.pref.tottori.lg.jp/ secure/1100571/pba_20171001.pdf. Japanese.

18 Japan Meteorological Agency [Internet]. Tokyo: Japan Meteorological Agency [cited 2018 Nov 1]. [Search past weather data]. Available from: https://www.data.jma.go.jp/obd/ stats/etrn/index.php. Japanese.

19 Schaffer A, Muscatello D, Broome R, Corbett S, Smith W. Emergency department visits, ambulance calls, and mortality associated with an exceptional heat wave in Sydney, Australia, 2011: A time-series analysis. Environ Health. 2012;11:3. PMID: 22273155.

20 Turner LR, Connell D, Tong S. The effect of heat waves on ambulance attendances in Brisbane, Australia. Prehosp Disaster Med. 2013;28:482-7. PMID: 23981779.

21 Bai L, Ding G, Gu S, Bi P, Su B, Qin D, et al. The effects of summer temperature and heat waves on heat-related illness in a coastal city of China, 2011-2013. Environ Res. 2014;132:212-9. PMID: 24815333.

22 Kenney WL, Munce TA. Invited review: Aging and human temperature regulation. J Apply Physiol. 2003;95:2598-603. PMID: 14600165.

23 Sugg MM, Konrad CE $2^{\text {nd }}$, Fuhrmann CM. Relationships between maximum temperature and heat-related illness across North Carolina, USA. Int J Biometeorol. 2016;60:66375. PMID: 26364040.

24 Bassil KL, Cole DC, Moineddin R, Lou W, Craig AM, Schwartz B, et al. The relationship between temperature and ambulance response calls for heat-related illness in Toronto, Ontario, 2005. J Epidemiol Community Health. 2011;65:82931. PMID: 21097937.

25 Alessandrini E, Zauli Sajani S, Scotto F, Miglio R, Marchesi S, Lauriola P. Emergency ambulance dispatches and apparent temperature: A time series analysis in Emilia-Romagna, Italy. Environ Res. 2011;111:1192-200. PMID: 21816396. 